\title{
When Gender Stereotypes Get Male Adolescents into Trouble: A Longitudinal Study on Gender Conformity Pressure as a Predictor of School Misconduct
}

\author{
Anke Heyder ${ }^{1}$ - Margriet van Hek ${ }^{2}$ - Mieke Van Houtte ${ }^{3}$ \\ Published online: 16 April 2020 \\ (C) The Author(s) 2020
}

\begin{abstract}
School misconduct is a threat to educational careers and learning. The present study sheds light on why male adolescents in particular are prone to school misconduct. Qualitative research has argued that male adolescents' construction of masculinity is a factor driving their school misbehavior. We examined the role of felt pressure to conform to gender stereotypes in predicting school misconduct among male and female adolescents. Data were provided by a three-wave panel study encompassing more than 4200 Flemish early adolescents (ages 12-14). Three-level growth curve models showed that male adolescents misbehaved more in school than female adolescents did. Male adolescents also demonstrated a steeper increase in school misconduct than female adolescents. Furthermore, greater felt gender conformity pressure predicted an increase in school misconduct in male adolescents but not in female adolescents. We conclude that school misconduct forms part of an enactment of masculine gender identity with detrimental consequences for male adolescents' educational achievement.
\end{abstract}

Keywords School misconduct $\cdot$ Human sex differences $\cdot$ Pressure for gender conformity $\cdot$ Sex roles $\cdot$ Gender identity $\cdot$ Behavior problems

Female adolescents outperform male adolescents in education throughout the Western world (Heckman and Lafontaine 2010; Van Hek et al. 2016; Voyer and Voyer 2014). However, the gender gap in academic achievement cannot be explained by cognitive differences between male and female adolescents (Heyder et al. 2017; Wang et al. 2013). Differences between male and female adolescents' behavior in school do seem crucial. Female students typically behave better in school, complying with school rules, listening and paying attention in class, and completing school assignments.

Electronic supplementary material The online version of this article (https://doi.org/10.1007/s11199-020-01147-9) contains supplementary material, which is available to authorized users.

Anke Heyder

anke.heyder@tu-dortmund.de

1 Department of Psychology, Technical University Dortmund, Emil-Figge-Str. 50, D - 44227 Dortmund, Germany

2 Department of Sociology, Radboud University, Nijmegen, The Netherlands

3 Department of Sociology, Ghent University, Ghent, Belgium
Male students tend to be more disruptive and aggressive in class and less diligent in their schoolwork (for students' selfreports, see Demanet and Van Houtte 2012a; Lam et al. 2012; for teachers' reports see Bertrand and Pan 2013; Jones and Myhill 2004). These behavioral differences help explain why females outperform males in school (DiPrete and Jennings 2012; Downey and Vogt Yuan 2005).

Not only is school misconduct detrimental to school achievement (Zimmermann et al. 2013), but it also is a contributor to teacher burnout (Aloe et al. 2014). Why students misbehave and how misbehavior relates to students' gender are therefore important questions. The current study focuses on the gender gap in school misconduct and its development during early adolescence. We used unique panel data to look beyond simple male-female differences and examine variation within the groups of male and female adolescents. Specifically, we investigated the role of felt pressure to conform to gender stereotypes in students' misconduct (Egan and Perry 2001). We tested whether felt pressure to conform to gender stereotypes predicted later school misconduct in male and in female adolescents, thus contributing to the gender gap in school misconduct as suggested by qualitative research (Jackson 2002, 2003; Morris 2012). 


\section{School Misconduct}

School misconduct, or school deviancy, can be defined as any rule-breaking or disruptive behavior in school (Stewart 2003). It ranges from disengagement and disciplinary problems, such as being late or copying homework, to smoking, drinking alcohol, and even violent or criminal behavior such as doing drugs during school hours (Aloe et al. 2014). In its mild form, misconduct is part of many students' and teachers' daily routine. But more serious school misconduct also occurs on a regular basis in many secondary schools (Sullivan et al. 2014). Misbehavior interferes with learning. Zimmermann et al. (2013) found school misconduct and achievement to be negatively and reciprocally related. That is, lowachieving students were more likely to show deviant behavior both within and outside of school (Hinshaw 1992; Zimmermann et al. 2013), and misbehavior has been negatively correlated with indicators of future achievement (Breslau et al. 2011; Lynch et al. 2014; Zimmermann et al. 2013). School misconduct is additionally a main stressor contributing to teachers' burnout (Aloe et al. 2014; Evers et al. 2004; Sullivan et al. 2014). Thus, it is crucial to better understand the origins of this behavior in order to develop strategies to prevent it.

Prior research has identified predictors of school misconduct at the level of the individual student, the teacher, and the school (for summaries, see Demanet 2013; SmithAdcock et al. 2013). For example, students' school belonging (Demanet and Van Houtte 2012a; Smith-Adcock et al. 2013) and self-efficacy (Demanet and Van Houtte 2019) have been found to protect students from developing a pattern of misconduct in school. Factors found to predict higher levels of school misconduct are growing up in an economically deprived family (Demanet and Van Houtte 2019), having low teacher support (Demanet and Van Houtte 2012b), and attending schools with a student population of diverse ethnicity (Demanet and Van Houtte 2011) or low socioeconomic background (Demanet and Van Houtte 2019).

Crucial for the current study, prior research has determined that male adolescents are more prone to school misconduct than female adolescents (Demanet and Van Houtte 2012a; Demanet and Van Houtte 2019; Geven et al. 2017). For instance, in a nationally representative sample of more than 20,000 U.S. students, male children and adolescents scored roughly half a standard deviation higher in disruptive behavior than female adolescents (Bertrand and Pan 2013). The opposite behavior (i.e., putting forth effort, paying attention and complying with rules) was more typical of female than male adolescents (Lam et al. 2012; Wang et al. 2011). Because school misconduct is negatively and reciprocally related to academic achievement (Zimmermann et al. 2013), it is considered one factor explaining gender differences in educational outcomes at the expense of male students (Downey and Vogt Yuan 2005).

However, very few quantitative studies have sought empirical explanations for why male adolescents exhibit more misconduct in school than female adolescents. With regard to student characteristics, scholars have found female adolescents' higher study involvement and prior achievement (Demanet et al. 2013) to be correlated with the (rising) gender gap in school misconduct. With respect to family background, Bertrand and Pan (2013) found a larger gender gap in school misconduct among students raised by a single mother. Additional analyses by these authors suggest that this was due, first, to single mothers investing more in their daughters and feeling emotionally closer to them than to their sons. Second, sons appeared to be more sensitive to (a lack of) parental input than daughters. No known quantitative studies have examined the pressure female and male adolescents feel to conform to gender norms, although qualitative studies have proposed this as an explanation of why male adolescents are more prone to school misconduct than female adolescents (Jackson 2002, 2003; Morris 2012).

\section{The Role of Pressure for Gender Conformity}

According to social cognitive theory (Bussey and Bandura 1999), social sanctions and self-sanctions are crucial in regulating gender-linked conduct. Here we focus on felt pressure for gender conformity as an aspect of students' gender identity (Egan and Perry 2001; Vantieghem et al. 2014). Felt pressure for gender conformity describes the degree to which individuals feel pressure from parents, peers, and self to exhibit gender-congruent behavior (Egan and Perry 2001). Captured with items such as "It is important to me to be like the other boys" and "I get mad if somebody says I am acting like a girl" (Vantieghem and Van Houtte 2015), felt pressure for gender conformity encompass both the use of gender-linked standards to judge oneself and the evaluative self-reaction after doing so.

Social cognitive theory holds that such self-regulatory processes produce gendered conduct and role-congruent behavior, leading in turn to feelings of self-satisfaction and selfworth (Bussey and Bandura 1999). Acquired gender schema thereby work as filters that facilitate the processing of genderrelated information (Bem 1981; for a recent review on the impact of gender schema theory, see Starr and Zurbriggen 2017). Past research has found stricter gender roles for male than for female children (Blakemore 2003; Skočajić et al. 2019; Wilbourn and Kee 2010). Studies on gender differences in felt pressure to conform have consistently reported that males feel greater pressure to conform to the male gender role than females with respect to the female gender role, both in childhood and in adolescence (Aoyagi et al. 2018; Egan and 
Perry 2001; Hoffman et al. 2019; Skinner et al. 2018; Vantieghem and Van Houtte 2015; Yunger et al. 2004).

In line with the self-regulatory mechanisms described by social cognitive theory (Bussey and Bandura 1999), we expect pressure for gender conformity to be differentially related to school misconduct in male and in female adolescents because male and female gender roles correspond differently with the behavior students are expected to demonstrate in school. More precisely, if the male (but not the female) gender role deviates from school norms, being more consistent with school misconduct, gender conformity pressure will increase school misconduct in male adolescents (but not in female adolescents) because school misconduct is perceived as a gender-congruent behavior in male adolescents (but not in female adolescents).

Various theories and evidence support this proposition. Sociological theories and qualitative studies on masculinity have described male adolescents' laddishness - that is, enactment of masculinity via resistance against authorities and rejection of school values such as effort and compliance - as clashing with school performance (Jackson 2002, 2003; Morris 2012). Furthermore, traditional gender stereotypes link being male or masculine to negative school behavior, such as inattentiveness, aggression, disruptiveness, and disrespect (Glock and Kleen 2017; Heyder and Kessels 2015; see Jones and Myhill 2004 for a qualitative study). Being diligent and well-behaved, on the other hand, is associated with femininity (Heyder and Kessels 2015, 2017; Kessels and Heyder 2017), suggesting that the traditional female gender role is generally more in line with the student role than the male gender role (reviews by Beaman et al. 2006; Duke 1978; Mickelson 1989). Note that there are also ways to enact femininity (e.g., via make-up, clothing or dating) that can signal rather low interest in academics (see Lyng 2009 for a qualitative study; McKenney and Bigler 2016). However, complying with these specific female gender norms would not automatically interfere with students' learning, as complying with traditional male gender norms would. With this in mind, we argue that male adolescents' and female adolescents' felt pressure to conform to gender stereotypes is a factor contributing to the gender gap in school misconduct.

To our knowledge, students' felt pressure to conform to gender stereotypes has never before been quantitatively studied in relation to school misconduct. Some research has examined the effects of gender norms at the societal level on educational attainment or standardized test scores, with mixed results. Some studies report better educational achievement among women in emancipatory climates (Marks 2008; Van Hek et al. 2016), whereas others find no correlations (ElseQuest et al. 2010; Stoet and Geary 2013, 2015). However, these studies measure emancipatory climates almost solely by indicators of women's status in society. Thus they do not necessarily provide insights on changing gender role expectations and the implications of these changes for men.
Moreover, these studies assume that all girls and boys or women and men, feel equally pressured to adhere to gender norms, which might not be the case. Most individual-level research on gender conformity pressure has focused on psychosocial adjustment, revealing a negative relation between the two constructs (Egan and Perry 2001; Yunger et al. 2004). Few studies have as yet linked gender conformity pressure with other antecedents of male adolescents' and female adolescents' academic achievement (see Vantieghem et al. 2014). The studies that are available identify gender as a crucial moderator of the relation between felt pressure for gender conformity and students' interests (Lagaert et al. 2017) and self-efficacy (Vantieghem and Van Houtte 2015).

In what follows, we refer to U.S. grade level equivalents when describing the school grades of Belgian students. The first grade of secondary school in Belgium corresponds with the seventh grade in the United States; students in this grade are 12 years-old on average. Lagaert et al. (2017) found that, for male seventh graders, pressure to conform to gender stereotypes was associated with less interest in so-called highbrow culture, that is, the arts and literature. For female seventh graders, a very small but positive effect emerged in line with the perception of the arts and literature as feminine (Nosek and Smyth 2011). Vantieghem and Van Houtte (2015) found a similar pattern for academic self-efficacy, defined as students' belief in their capability to perform a certain academic task (Bandura 1997). Academic self-efficacy is considered a powerful predictor of future academic achievement (Usher et al. 2019).

Regarding gender conformity pressure, Vantieghem and Van Houtte (2015) found that, at the end of the seventh grade, felt pressure to conform to gender stereotypes predicted lower levels of self-efficacy in male adolescents, whereas selfefficacy in female adolescents remained stable. These authors found no significant relationship between gender conformity pressure and self-efficacy at the beginning of the seventh grade (Vantieghem and Van Houtte 2015), indicating that gender conformity pressure might start to play a role during the seventh grade. The authors explained this change by the fact that the seventh grade is the first year of secondary school in Belgium. Because schools differ in their gender norms (Van Houtte 2004) and compliance with norms increases with exposure (Derks and Vermeersch 2001), it might simply reflect the time it takes for students to become familiar with the gender norms at their new school.

In sum, prior research suggests that felt pressure to conform to gender stereotypes is negatively correlated with interest in the arts and literature and academic self-efficacy in male adolescents, but not necessarily in female adolescents. The current study extends this line of research by studying the genderspecific effect of felt pressure to conform to gender stereotypes on school misconduct. The variable school misconduct 
is very important, not only for students' own educational careers, but also for their peers and teachers.

\section{Development in Adolescence}

Adolescence is an exciting phase in a young person's life and a critical period of identity development (Erikson 1968). To investigate the effect of gender conformity pressure on school misconduct, we used data from a panel of students in Flanders, the Dutch-speaking part of Belgium, from the start of seventh grade to the end of eighth grade (ages 12-14). These data were particularly suited for studying the development of school misconduct for two reasons.

First, as we noted, the seventh grade is the first year of secondary school in Belgium. School transitions are considered a major life event, bringing academic and social challenge and threat (Sirsch 2003). The more students feel their self-esteem is under threat in their new learning environment, the greater their likelihood of showing deviant behavior (Donnellan et al. 2005; Zimmermann et al. 2013). Thus, an increase in school misconduct in the first years of secondary school seems plausible, although this point has not yet been fully confirmed by research. Longitudinal studies on problem behavior in general, that is, deviant behavior not limited to the school context, have found an increase in misbehavior in adolescence (Duncan et al. 2001; Véronneau and Dishion 2010). Cross-sectional studies with different age groups report higher levels of school misconduct in older than in younger adolescents (Demanet and Van Houtte 2012a). Although these findings generally suggest that school misconduct increases in adolescence, their crosssectional study design does not enable potential cohort effects to be ruled out, something which longitudinal panel data such as ours can do.

Second, the onset of puberty occurs at the beginning of adolescence, a time when peer pressure is at its peak (Steinberg and Monahan 2007; Veenstra et al. 2013). The gender intensification hypothesis (Hill and Lynch 1983) argues that the gendered physical development that occurs during puberty increases young people's awareness of gender roles and gender norms. Thus, during adolescence, gender conformity pressure might increase in both intensity, as has been found for peer influence in general (Steinberg and Monahan 2007), and its predictive effect. Empirical findings on the development of gender conformity pressure are mixed. In a sample of U.S. third to seventh graders followed over a year, pressure decreased for female students (Yunger et al. 2004). Pressure remained stable for male students in Grades 3 and 4, whereas it increased for male students in Grades 5-7.

A recent study with French students in Grades 6-9 differentiated not only between male and female adolescents, but also between students of North African and European descent (Hoffman et al. 2019). Among female adolescents, Hoffman et al. (2019) found decreasing gender conformity pressure, as did Yunger et al. (2004), irrespective of the female adolescents' ethnic background. For male adolescents of European descent, pressure remained stable, whereas for male adolescents of North African descent, pressure increased (Hoffman et al. 2019). Furthermore, Vantieghem and Van Houtte (2015) found that gender conformity pressure predicted lower academic self-efficacy in male adolescents only at the end of seventh grade, and not at the beginning of that grade or in female adolescents. This pattern suggests that felt pressure is more influential for male adolescents than female adolescents and that its importance increases in secondary school. These theories and findings call for a longitudinal perspective in studying the role of gender conformity pressure in the gender gap in school misconduct.

\section{The Present Study}

School misconduct interferes with learning and is also a major stressor for teachers, so it is important to better understand its origins. Male adolescents, in particular, are prone to school misconduct. Our interest in the present study is the role of gender conformity pressure in the development of school misconduct among students. Both the insecurity induced by the transition to a new school (Sirsch 2003) and the increasing awareness of gender roles at the start of puberty (Hill and Lynch 1983) point to the value of using a longitudinal framework to study the relation between gender conformity pressure and development of school misconduct in early adolescents. Thus, we used multilevel panel data to address our research question: Does gender conformity pressure differentially contribute to the level and development of school misconduct in male adolescents and in female adolescents from the beginning of the seventh grade to the end of the eighth grade?

For this period, we expected male adolescents to exhibit more misconduct in school than female adolescents (Hypothesis 1). Second, we expected the increase in school misconduct during this period to be more pronounced in male adolescents than in female adolescents (Hypothesis 2). Third, we expected male adolescents' school misconduct to increase more if they felt greater pressure to conform to gender norms (Hypothesis 3). We did not expect increases in school misconduct among female adolescents to be related to pressure to conform to gender norms. Our use of rich, multilevel panel data extends on prior studies on gender conformity pressure, which were either qualitative in nature (Morris 2012) or did not include school misconduct (Hoffman et al. 2019; Yunger et al. 2004). 


\section{Method}

\section{Sample}

Our analyses were based on three-wave longitudinal data from a representative sample of 4987 Flemish adolescents collected within the "Teaching in the Bed of Procrustes" project. Prior to data collection, the use of child assent was approved by the involved schools and the Belgian Commission for the Protection of Privacy, based on the minimal risk of the study. Anonymity was guaranteed. To obtain a sample of schools representative of Flanders (the Dutch speaking northern part of Belgium), a disproportional stratified sampling method was employed with school selection dependent on the region, school denomination, and urbanization level. (For details on data collection, see also Vantieghem 2016.) Taking these parameters into account, three random samples of schools in Flanders were drawn. If a school from the first sample rejected the invitation to participate, a school with the same characteristics (region, denomination, and urbanization) from the second sample was chosen to replace it. Of the 124 contacted schools, 59 participated, which translates into a response rate of $47.6 \%$. Mostly schools rejected because they were already participating in another research project or because of work pressure among staff. The 59 participating schools did not differ from other Flemish secondary schools in terms of their sector (i.e., public vs. state-subsidized "private" school), curriculum, and student composition (see Vantieghem 2016, pp. 64, 65; see Table 1s in the online supplement).

We analyzed all three waves of the "Teaching in the Bed of Procrustes" data. The first wave was collected in the fall of 2012, when the students had just started seventh grade (the first grade of secondary school). The second wave was collected in the spring of 2013, when the students were at the end of seventh grade. The third wave was collected in the spring of 2014, when the students were at the end of eighth grade. The data were collected by means of a paper survey form which students filled in at school; the students were assured of the survey's confidentiality. The response rate at the student level was $96.9 \%$, and 6380 students were surveyed in the first wave. Only students who participated in all three waves with no missing values were included in the current study, yielding a final analytic sample of 4209 students $(66 \%$ of all students that participated in Wave 1) nested in 57 schools. These students did not differ greatly from the total Flemish student population: $49.5 \%(n=2085)$ of the sample was female, $82.7 \%(n=$ 1160 ) was on track (i.e., had not repeated or skipped a grade), 4.5\% $(n=190)$ did not speak Dutch with either their father or mother, and $4.8 \%(n=201)$ did not have Belgian nationality. Students were on average $12.14(S D=0.44$, range $=10-15)$ years old at Wave 1.

\section{Measures}

\section{School Misconduct}

Our dependent variable was students' school misconduct, measured by a 17 -item scale inspired by Stewart (2003, pp. 602-604) and often used for adolescents (Demanet and Van Houtte 2012a; Demanet et al. 2013). Crosnoe (2002) remarked that although assessing deviant behavior through self-reports presents difficulties, it is still the most economical and common method of gathering this information. We took the mean of the 17 items, which asked students how often they exhibited certain behavior, such as being late for school, skipping classes, fighting at school, and smoking at school. Students could answer (0) never, (1) rarely, (2) sometimes, (3) often or (4) very often. An English translation of all items can be found in Demanet and Van Houtte (2012a). We coded this variable as missing if students had more than $50 \%$ missing values. Otherwise, the mean of the remaining questions was used. Cronbach's alphas for Waves 1, 2 and 3 were .80, .81 and .84 , respectively. Because there was great variation in the severity of the school misconduct indicators, and some occurred only sporadically in the data, we performed a robustness check in which school misconduct consisted of 13 items, omitting fighting, stealing, vandalism, and drug use in school. Results did not differ substantially (if anything, the effects found were stronger with higher statistical significance).

\section{Pressure for Gender Conformity}

Pressure for gender conformity was assessed using the corresponding subscale from the gender identity questionnaire by Egan and Perry (2001). This measure consists of eight items related to pressure from peers and from oneself to conform to gender stereotypes (see also Vantieghem and Van Houtte 2015). Female and male adolescents were given different items, although most greatly overlapped. For example, female adolescents got the statement: "I get mad if somebody says I am acting like a boy," and male adolescents got: "I get mad if somebody says I am acting like a girl." Some statements did differ however. Female adolescents, for example, got: "The girls I know would mind if I told them I wanted to learn to play soccer," whereas male adolescents got: "The boys I know would mind if I told them I wanted to learn ballet or gymnastics." Respondents were asked whether they $(0)$ completely disagreed, (1) disagreed, (2) agreed or (3) completely agreed with these statements. Cronbach's alphas for female adolescents in the three waves were $.84, .88$ and .87 , respectively, and for male adolescents were $.81, .83$ and .84. An English translation of all items can be found in Vantieghem and Van Houtte (2015). 


\section{Gender}

Students' gender was coded as the variable female, on which female adolescents scored 1 and male adolescents scored 0 .

\section{Control Variables}

First, we controlled for students' traditional gender role attitudes to take into account how progressive or traditional students' gender role beliefs were. Traditional gender role attitudes were measured by a 15-item scale (Vermeersch et al. 2010). Respondents were presented with statements such as: "It is best for everyone if the man makes the decisions in the family," "There has to be something wrong with a boy who has ballet as a hobby," and "A woman should in the first place think about her kids, not her career." They indicated whether they (0) completely disagreed, (1) disagreed, (2) neither agreed nor disagreed, (3) agreed or (4) completely agreed. Cronbach's alphas for the three waves were $.79, .84$ and .85 , respectively. We averaged across items such that higher scores indicate stronger endorsement of traditional gender role attitudes. The unidimensionality of this scale was previously supported by Huyge et al. (2014). Because we were interested in the pressure students felt to adhere to gender norms, we treated traditional gender role attitudes as a control variable. Robustness checks showed that the interaction between this variable and gender conformity pressure was not statistically significant.

We also controlled for students' emotional well-being because this could affect their school conduct. For this measure, we used a 12-item scale measuring positive and negative affect (Keyes et al. 2002). Examples items were: "How often have you felt content in the last 30 days," "How often have you felt restless or nervous in the last 30 days," and "How often have you felt very happy in the last 30 days." Answer categories were (0) very often, (1) often, (2) sometimes, (3) rarely or (4) never. Based on the principal component analyses by Vantieghem et al. (2014) showing unidimensionality, the positive and negative affect items were combined into one averaged scale with the items referring to negative affect reverse-coded so that a higher score indicates better emotional well-being. Cronbach's alphas for the scale were .81, .86 and .87 , respectively, for the three waves.

We also controlled for students' initial ability in math, because educational achievement has been found to be inversely related to school misconduct (Zimmermann et al. 2013). This variable was measured only in Wave 1 . Students completed a grade-appropriate mathematics test consisting of 50 questions on problems and calculations (Dudal 2003). This test was scored by counting correctly answered items with actual performance ranging from 0 to 50 correctly answered items. We furthermore controlled for whether students were enrolled in a vocational track $(0 / 1)$ (time varying) because research has shown students in vocational tracks to be more prone to school misconduct (Van Houtte and Stevens 2008).

We included two variables on students' familial background because family features may influence students' school misconduct as well as other variables in our models (e.g., emotional well-being; Jenkins 1995). First, we controlled for parental socioeconomic status by incorporating information on the employment status of parents. Students were asked about the current or last occupation of their mother and father. If information was missing, we used information from the parental questionnaire. All occupations were recoded based on the classification of Erikson, Goldthorpe, and Portocarero (EGP-classification, for a discussion, see Erikson and Goldthorpe 2002). This ranged from (1) unskilled manual laborer to (8) high-grade professional or manager. We took the score of the parent with the higher socioeconomic status (Erikson and Goldthorpe 1992; Forehand et al. 1987). Second, we controlled for whether the students were native (i.e., born in Belgium) (1/0). Lastly, we controlled for students' birthyear (linearly and mean-centered) because some students had skipped or repeated a year.

\section{Missing Values}

A total of $778(15.6 \%)$ students participating in all three waves had a missing value on one or more of our variables. Most missing values were on the dependent variable: 286 students had missing information on their school misconduct in at least one of the three waves. Also, information on math ability was missing for 238 students. We listwise deleted all students with one or more missing values, resulting in a dataset of 12,627 observations (student-year combinations), encompassing 4209 students $(66 \%$ of the sample in Wave 1) and 57 schools.

\section{Analytic Strategy}

To test our hypotheses, we employed three-level growth curve models in R (R package LME: Linear Mixed-Effects Models). In our models, observations (i.e., student-wave combinations) are nested in students, which are nested in schools. We set the intercept and the linear effect of time at random at all levels. Time is included as 0,1 and 2 in the models for sake of interpretation of the interaction effects. Model 0 is the null model from which we determined the variance in school misconduct at the three levels. In Model 1, we added time indicators (wave and wave-squared) to test whether students' school misconduct changed over time and to see whether such change was linear. In Model 2, we added the variable "female" to see whether female or male adolescents displayed school misconduct more often. In this model we tested Hypothesis 1. In Model 3, we added explanatory and control variables and the interaction female*wave to test whether the change in school misconduct over the school career differed between 
female and male adolescents. In this model we tested Hypothesis 2. When an interaction is included in a model, the main effects refer to students who score 0 on the variables in the interaction. Thus the effect of wave in Model 3 refers to male adolescents (who score 0 on "female"). The interaction coefficient indicates the difference in the effect of wave between female and male adolescents. The effect of wave for female adolescents is found by adding the interaction effect to the main effect. In Model 4, we tested Hypothesis 3. The three-way interaction female*conformity*wave shows whether female and male adolescents' development of school misconduct is dependent on the level of gender conformity pressure they experience. In order to better understand the genderspecific developmental effect indicated by the three-way interaction in Model 4, Model 4 is also presented separately for female and male adolescents.

Because our data have three time points, only one random parameter could be included in the models (Snijders and Bosker 2012). For this reason, the linear slope of wave was allowed to vary across students and schools, but the quadratic slope of wave was not. Models with random quadratic growth parameters do not converge with this type of data (Singer and Willett 2003). We could thus predict growth rates, but we could not draw conclusions on predictors of growth acceleration. As a robustness check, we ran all models with time included as a factor (i.e., dummy variables) to account for the non-linear nature of this variable. Wave 1 (coded as 0 ) was the reference category. (The results of these analyses can be found in Tables $3 \mathrm{~s}$ and $4 \mathrm{~s}$ in the online supplement.) These models produced practically the same results with the exception that they show that the school misconduct of female adolescents who experience a high level of pressure to gender conformity decreases between Waves 1 and 3. In our main models time is included linearly and quadratically because this approach fits the data better than when time is included as a factor.

\section{Results}

\section{Descriptive Results}

Table 1 presents the descriptive statistics for all variables separately for the three waves. (For a presentation of descriptive statistics separately for female and male adolescents, please see Table $2 \mathrm{~s}$ in the online supplement.) Table 2 shows the bivariate correlations between all our variables in Wave 3 for male adolescents (above the diagonal) and for female adolescents (below the diagonal). In this matrix we see that in Wave 3 , uncontrolled for other variables, the correlation between gender conformity pressure and school misconduct was almost 14 times stronger for male adolescents than for female adolescents.

\section{Development of School Misconduct}

The null model for school misconduct indicated significant variance within students $(\sigma=.054)$, between students $(\sigma=.047)$ and between schools $(\sigma=.005)(p<.001$ for all three). This means that school misconduct varied over time (within-student variance), between students (between-student variance), and between schools (between-school variance). The variance parameters further resulted in an intraclass correlation of .443 at the student level and .047 at the school level, indicating that $44.3 \%$ of the variation in school misconduct can be attributed to between-student differences and $4.7 \%$ to between-school differences, stressing the need to apply multilevel modeling to test our hypotheses. Results from all following three-level growth curve models are presented in Table 3. In Model 1, we see that the students' school misconduct increased over the three waves and that the rise was nonlinear (see Table 3). Compared to the null model (see previous), the within- and between-student variance dropped by $43 \%$ and $28 \%$, respectively, and the variance between schools, which was low to begin, dropped by $40 \%$. This pattern indicates that students' school misconduct was largely explained by the time point in their school career.

\section{Gender Differences in School Misconduct}

Our first hypothesis predicted that male adolescents will exhibit more misconduct in school than female adolescents. This difference was supported by the negative regression coefficient for female adolescents in Model 2 (see Table 3). Second, we expected the increase in school misconduct to be stronger in male than in female adolescents (Hypothesis 2). In Model 3, the main effect of wave indicates the increase in school misconduct of male adolescents (who score 0 on female) over time. The interaction female*wave indicates the difference in the increase in school misconduct between female and male adolescents. For male adolescents, the increase $(b=0.057)$ was significantly steeper than for female adolescents $(b=0.057-0.012=0.045)$, supporting Hypothesis 2. Furthermore, students reporting high levels of gender conformity pressure and those with traditional gender role attitudes displayed higher levels of school misconduct. In an additional analysis, we found that the effect of gender conformity pressure on the overall level of school misconduct did not differ significantly between male and female adolescents. Note however that our second and third hypotheses refer to increases in school misconduct rather than the overall level. Students born in Belgium, students with higher math ability, and those with greater emotional well-being reported less school misconduct.

Third, we expected male adolescents' school misconduct to increase more if they experienced more pressure to conform to gender norms (Hypothesis 3), whereas female adolescents' 
Table 1 Descriptive statistics of three-waves "Teaching in the Bed of Procrustes" data

\begin{tabular}{|c|c|c|c|c|c|c|}
\hline \multirow[t]{2}{*}{ Variables } & \multicolumn{2}{|l|}{ Wave 1} & \multicolumn{2}{|l|}{ Wave 2} & \multicolumn{2}{|l|}{ Wave 3} \\
\hline & $M(S D)$ & Range & $M(S D)$ & Range & $M(S D)$ & Range \\
\hline School misconduct & $0.270(0.255)$ & $0-2.706$ & $0.339(0.294)$ & $0-3.353$ & $0.472(0.375)$ & $0-3.294$ \\
\hline Female adolescent & $.495(.500)$ & $0-1$ & $.495(.500)$ & $0-1$ & $.495(.500)$ & $0-1$ \\
\hline Gender conformity pressure & $1.265(0.730)$ & $0-3$ & $1.253(0.689)$ & $0-3$ & $1.248(0.732)$ & $0-3$ \\
\hline Traditional gender role attitudes & $1.588(0.542)$ & $0-3.800$ & $1.607(0.578)$ & $0-3.867$ & $1.625(0.603)$ & $0-4$ \\
\hline Emotional well-being & $2.883(0.496)$ & $0.360-4$ & $2.899(0.558)$ & $0.250-4$ & $2.752(0.616)$ & $0-4$ \\
\hline Initial ability in math ${ }^{1}$ & $28.646(1.004)$ & $0-50$ & & & & \\
\hline Vocational track & $.063(.244)$ & $0-1$ & $.069(.254)$ & $0-1$ & $.288(.453)$ & $0-1$ \\
\hline Parental socioeconomic status ${ }^{1}$ & $5.295(1.777)$ & $1-8$ & & & & \\
\hline Native $^{\mathrm{a}}$ & $.952(.213)$ & $0-1$ & & & & \\
\hline Birthyear ${ }^{\mathrm{a}, \mathrm{b}}$ & $1999.856(0.439)$ & 1997-2002 & & & & \\
\hline $\operatorname{Age}^{\mathrm{a}}$ & $12.144(0.439)$ & $10-15$ & & & & \\
\hline
\end{tabular}

$n$ schools $=57 ; n$ students $=4209 ; n$ observations $=12,627$

${ }^{\mathrm{a}}$ Only measured in Wave $1 .{ }^{\mathrm{b}}$ This variable is mean-centered in the analyses

increase in school misconduct was not expected to be related to pressure to conform to gender norms. Model 4 includes the crucial interaction of female*pressure for gender conformity*wave (and all its lower level interactions) to test Hypothesis 3. This interaction was statistically significant, indicating that the influence of gender conformity pressure on changes in school misconduct over the school career differed significantly between female and male adolescents.

To better understand this gender-specific developmental effect, we re-ran the analysis separately for female and male adolescents (see Table 4). For clarity we will discuss the coefficients of Table 4. In Table 4, the significant main effects of wave indicate an increase in school misconduct for female adolescents and male adolescents who scored 0 on gender conformity pressure. The interactions wave*conformity indicate how this increase changes when gender conformity pressure increases by one unit (the range of gender conformity pressure is $0-3$ ). Because this two-way interaction was not statistically significant for female adolescents, we can conclude that female adolescents showed the same increase in school misconduct over their school career. For male adolescents, however, this interaction is positive and statistically significant. Further probing indicates that the increase in school misconduct becomes stronger as male adolescents experience more pressure for gender conformity. Both the interaction wave*pressure for gender conformity as well as the non-linear increase in school misconduct are also apparent from Fig. 1. In Fig. 1a, the lines for female adolescents with the lowest and highest values of gender conformity pressure (i.e., 0 and 3) are largely parallel. In Fig. $1 \mathrm{~b}$ the line for male

Table 2 Bivariate correlations at wave 3, separately for female and male adolescents

\begin{tabular}{|c|c|c|c|c|c|c|c|c|c|}
\hline \multirow[t]{2}{*}{ Variables } & \multicolumn{9}{|c|}{ Correlations } \\
\hline & 1 & 2 & 3 & 4 & 5 & 6 & 7 & 8 & 9 \\
\hline 1. School misconduct & - & $.096^{*}$ & $.224 *$ & $-.195^{*}$ & $-.170^{*}$ & $.069 *$ & $-.089^{*}$ & $-.064 *$ & $-.138 *$ \\
\hline 2. Gender conformity pressure & .007 & - & $.376^{*}$ & $-.143 *$ & $-.078^{*}$ & $.129 *$ & $-.111 *$ & -.024 & $-.067 *$ \\
\hline 3. Traditional gender role attitudes & $.104 *$ & $.339 *$ & - & $-.065^{*}$ & $-.187 *$ & $.157 *$ & $-.185^{*}$ & $-.110 *$ & $-.152 *$ \\
\hline 4. Emotional well-being & $-.268 *$ & $-.135^{*}$ & $-.065^{*}$ & - & $.087 *$ & -.040 & .030 & $.056^{*}$ & $.067 *$ \\
\hline 5. Inital ability in math & $-.137 *$ & $-.045^{*}$ & $-.154 *$ & $.123^{*}$ & - & $-.449 *$ & $.291 *$ & $.089 *$ & $.340^{*}$ \\
\hline 6. Vocational track & $.061 *$ & $.052 *$ & $.092 *$ & $-.114 *$ & $-.479 *$ & - & $-.350^{*}$ & -.009 & $-.292^{*}$ \\
\hline 7. Parental socioeconomic status ${ }^{\mathrm{a}}$ & $-.072 *$ & $-.046^{*}$ & $-.180^{*}$ & $.136^{*}$ & $.319 *$ & $-.336 *$ & - & $.143 *$ & $.257 *$ \\
\hline 8. Native (vs. immigrants) ${ }^{\mathrm{a}}$ & -.033 & .021 & $-.059 *$ & .030 & $.106^{*}$ & -.032 & $.168^{*}$ & - & $.263^{*}$ \\
\hline 9. Birthyear $^{\mathrm{a}}$ & $-.073 *$ & .015 & $-.112 *$ & $.081 *$ & $.340 *$ & $-.309 *$ & $.287 *$ & $.181 *$ & - \\
\hline
\end{tabular}

Coefficients above the diagonal are for male adolescents $(n=2124)$; coefficients below the diagonal are for female adolescents $(n=2085)$

${ }^{\text {a }}$ Only measured in Wave 1

$* p<.05$ 
Table 3 Three-level growth curve models predicting school misconduct

\begin{tabular}{|c|c|c|c|c|}
\hline & $\begin{array}{l}\text { Model } 1 \\
B(S E)\end{array}$ & $\begin{array}{l}\text { Model } 2 \\
B(S E)\end{array}$ & $\begin{array}{l}\text { Model } 3 \\
B(S E)\end{array}$ & $\begin{array}{l}\text { Model } 4 \\
B(S E)\end{array}$ \\
\hline Intercept & $0.284(0.008)^{* * *}$ & $0.330(0.009) * * *$ & $0.545(0.029)^{* * *}$ & $0.558(0.030)^{* * *}$ \\
\hline Wave & $0.047(0.009)^{* * *}$ & $0.046(0.009)^{* * *}$ & $0.057(0.009)^{* * *}$ & $0.035(0.012)^{* * * *}$ \\
\hline Wave-squared & $0.032(0.003) * * *$ & $0.032(0.003)^{* * *}$ & $0.027(0.003)^{* * * *}$ & $0.027(0.003)^{* * * *}$ \\
\hline Female & & $-0.098(0.008)^{* * *}$ & $-0.081(0.008) * * *$ & $-0.092(0.014)^{* * *}$ \\
\hline Gender conformity pressure & & & $0.008(0.004)^{* *}$ & $0.000(0.006)$ \\
\hline Socioeconomic status ${ }^{\mathrm{a}}$ & & & $0.001(0.002)$ & $0.001(0.002)$ \\
\hline Birthyear $^{\mathrm{b}}$ & & & $-0.028(0.009)^{* * *}$ & $-0.028(0.009)^{* * *}$ \\
\hline Native $0 / 1^{\mathrm{a}}$ & & & $-0.031(0.017)^{*}$ & $-0.031(0.017)^{*}$ \\
\hline Initial ability in math ${ }^{\mathrm{a}}$ & & & $-0.002(0.000)^{* * *}$ & $-0.002(0.000)^{* * *}$ \\
\hline Vocational track 0/1 & & & $-0.015(0.009)$ & $-0.015(0.009)^{*}$ \\
\hline Emotional well-being & & & $-0.080(0.004)^{* * *}$ & $-0.080(0.005)^{* * *}$ \\
\hline Traditional gender role attitudes & & & $0.042(0.005)^{* * *}$ & $0.042(0.005)^{* * *}$ \\
\hline \multicolumn{5}{|l|}{ Interactions } \\
\hline Female*wave & & & $-0.012(0.005)^{* *}$ & $0.011(0.011)$ \\
\hline Female*conformity & & & & $0.006(0.010)$ \\
\hline Wave*conformity & & & & $0.014(0.005)^{* * *}$ \\
\hline Female*conformity*wave & & & & $-0.016(0.008)^{* *}$ \\
\hline \multicolumn{5}{|l|}{ Variance parameters } \\
\hline Variance within students & .031 & .031 & .030 & .030 \\
\hline Variance between students & .034 & .032 & .029 & .030 \\
\hline Variance slope (time) over students & .012 & .012 & .011 & .011 \\
\hline Variance between schools & .003 & .002 & .002 & .002 \\
\hline Variance slope (time) over schools & .001 & .001 & .001 & .001 \\
\hline
\end{tabular}

$n$ schools $=57 ; n$ students $=4209 ; n$ observations $=12,627$

${ }^{a}$ This information was only measured in Wave 1 and is not time-variant. ${ }^{\mathrm{b}}$ This variable is not time-variant

$* p<.05 . * * p<.01 . * * * p<.001$

adolescents who reported the greatest gender conformity pressure $(=3)$ is steeper than that for male adolescents who scored lowest on gender conformity pressure $(=0)$. The increase in school misconduct in male adolescents between Waves 1 and 3 was 0.23 and 0.14 , respectively, for male adolescents reporting high gender conformity pressure and those reporting low gender conformity pressure. So, male adolescents who experienced a lot of pressure to behave according to gender norms exhibited a stronger increase in school misconduct over their school career than male adolescents who experienced less pressure to behave according to gender norms. These findings support Hypothesis 3.

\section{Discussion}

Previous studies have shown male adolescents to be more prone to school misconduct than female adolescents (Bertrand and Pan 2013; Geven et al. 2017). Yet, very few quantitative studies have assessed possible explanations for gender differences in school misconduct. School misconduct is a key factor in individual and gender differences in academic achievement (Downey and Vogt Yuan 2005), and it is detrimental to teachers' well-being (Aloe et al. 2014). It is therefore important to better understand the origins of this behavior and ways to prevent it. Although qualitative studies have indicated that gender norms might explain why male adolescents are more likely to misbehave in school than female adolescents (Jackson 2002, 2003; Morris 2012), this relationship is not known to have been investigated quantitatively.

The central objective of our study was to do just that. We investigated whether felt pressure to conform to gender stereotypes predicted the differential development of school misconduct in male and in female adolescents, thereby contributing to an increasing gender gap in school misconduct in early adolescence. Based on three-wave panel data from more than 4200 Flemish female and male adolescents, we found that, as expected, male adolescents exhibited more school misconduct and displayed a larger increase in school misconduct than female adolescents. Furthermore, in accordance with our hypothesis, only for male adolescents, the increase in school misconduct became stronger the more gender conformity 
Table 4 Model 4 separately for female and male adolescents

\begin{tabular}{|c|c|c|}
\hline & $\begin{array}{l}\text { Female } \\
\text { adolescents } \\
B(S E)\end{array}$ & $\begin{array}{l}\text { Male adolescents } \\
B(S E)\end{array}$ \\
\hline Intercept & $0.421(0.032)^{*}$ & $0.626(0.046)^{* * *}$ \\
\hline Wave & $0.056(0.011)^{* * *}$ & $0.019(0.016)$ \\
\hline Wave-squared & $0.020(0.004)^{* * *}$ & $0.034(0.006)^{* * *}$ \\
\hline Gender conformity pressure & $0.011(0.006)^{*}$ & $-0.005(0.007)$ \\
\hline Socioeconomic status ${ }^{\mathrm{a}}$ & $0.002(0.003)$ & $-0.001(0.003)$ \\
\hline Birthyear $^{\mathrm{b}}$ & $-0.020(0.012)^{*}$ & $-0.033(0.013)^{* *}$ \\
\hline Native $0 / 1^{\text {a }}$ & $-0.009(0.020)$ & $-0.060(0.028)^{* *}$ \\
\hline Initial ability in math ${ }^{\mathrm{a}}$ & $-0.001(0.001)^{* *}$ & $-0.003(0.001)^{* * *}$ \\
\hline Vocational track $0 / 1$ & $-0.003(0.012)$ & $-0.026(0.013)^{*}$ \\
\hline Emotional well-being & $-0.071(0.005)^{* * *}$ & $-0.091(0.007)^{* * *}$ \\
\hline $\begin{array}{l}\text { Traditional gender role } \\
\text { attitudes }\end{array}$ & $0.021(0.007)^{* * *}$ & $0.058(0.008)^{* * *}$ \\
\hline \multicolumn{3}{|l|}{ Interaction } \\
\hline Wave*conformity & $-0.002(0.005)$ & $0.014(0.006)^{* *}$ \\
\hline
\end{tabular}

$n$ female adolescents $=2085, n$ male adolescents $=2124$

${ }^{a}$ This information was only measured in Wave 1 and is not time-variant.

${ }^{\mathrm{b}}$ This variable is not time-variant

$* p<.05 . * * p<.01 . * * * p<.001$

pressure male adolescents experienced. So, the more pressure male adolescents felt to adhere to gender norms, the larger their increase in school misconduct during the first 2 years of secondary school. This finding sheds new light on why male adolescents exhibit more school misconduct than female adolescents because previous research focused on study behaviors, academic results or family structure in this respect (Bertrand and Pan 2013; Demanet et al. 2013).

Our core finding - that for male adolescents in our sample, the increment of misconduct was correlated with pressure for gender conformity - indicates that misconduct is bound with male identity formation and enactment of masculinity in adolescence. Our quantitative results corroborate sociological theories and previous qualitative findings on the function of misconduct and rejection of school rules and authorities as a signal of masculinity among male adolescents (Jackson 2002, 2003; Morris 2012). In pointing out how male identity formation can conflict with success in school (Kessels et al. 2014), our results complement prior findings on the negative relation between gender conformity pressure and male adolescents' sense of self-efficacy (Vantieghem and Van Houtte 2015) and interests (Lagaert et al. 2017).

Interestingly, female adolescents' increment in school misconduct was unrelated to felt pressure for gender conformity, which is in line with the proposition that femininity, compared to masculinity, is not (or much less) counter to school rules and culture (Mickelson 1989). In addition, female adolescents reported less gender conformity pressure than male adolescents, and pressure descriptively even decreased over time in female adolescents in

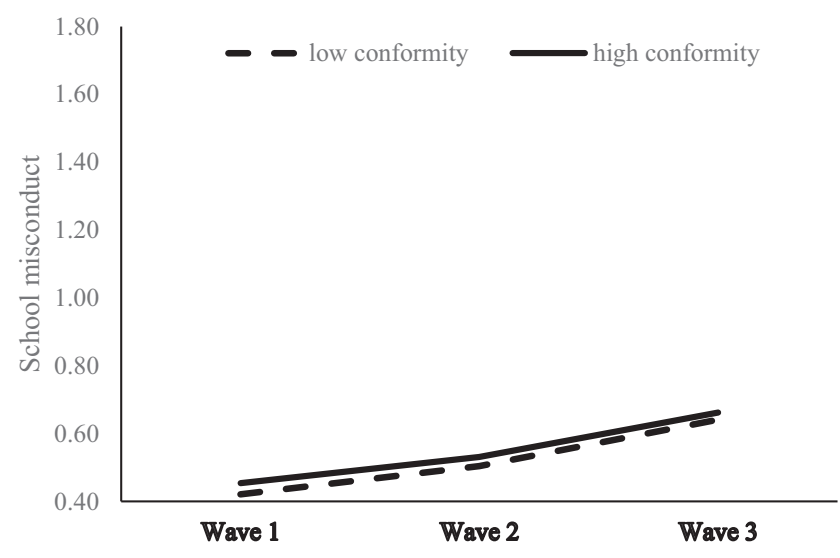

(a) Female adolescents

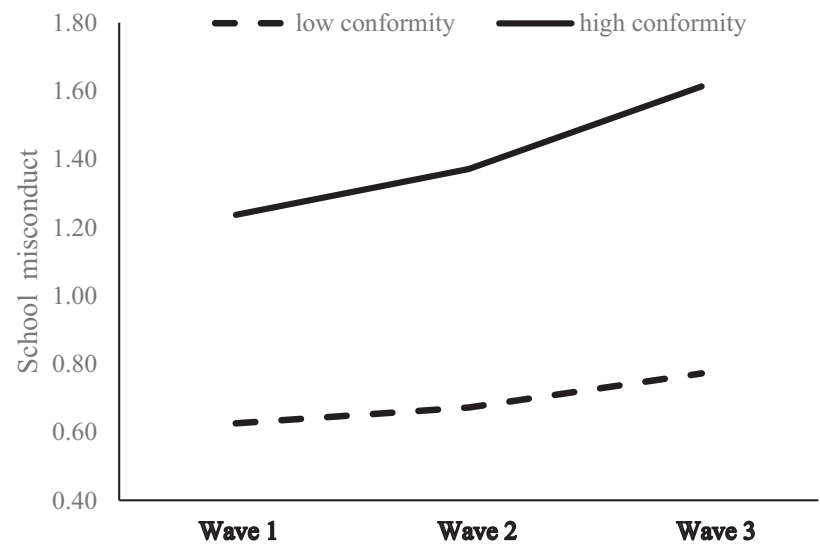

(b) Male adolescents

Fig. 1 School misconduct for (a) female adolescents and (b) male adolescents with low and high felt pressure for gender conformity. Low pressure $=0 ;$ high pressure $=3$

our sample (see Table $2 \mathrm{~s}$ in the online supplement) and others (Aoyagi et al. 2018; Hoffman et al. 2019; Yunger et al. 2004), supporting research indicating that gender roles are more relaxed for females than for males (Blakemore 2003; Skočajić et al. 2019; Wilbourn and Kee 2010).

From a theoretical perspective, our findings can be interpreted as mostly supportive of social cognitive theory (Bussey and Bandura 1999) and gender intensification theory (Hill and Lynch 1983). In our sample, evaluative selfreactions after judging oneself according to a gender-linked standard - as part of students' felt pressure for gender conformity - did predict gender-congruent behavior in male adolescents (i.e., school misconduct), as theoretically expected (Bussey and Bandura 1999). In line with gender intensification theory (Hill and Lynch 1983), pressure for gender conformity descriptively increased in male adolescents in the period of focus.

However, our findings that both variables were unrelated in female adolescents and pressure for gender conformity 
decreased in female adolescents do not fit well with these theoretical frameworks. One potential explanation for the latter finding could be the fact that female adolescents on average enter puberty 1.5 years earlier than male adolescents (Negriff and Susman 2011). Thus, in our sample the salience of gender norms might have already decreased in female adolescents, whereas they were still at peak or even increasing in male adolescents. Regarding the relation between female adolescents' pressure for gender conformity and their school misconduct, we might speculate that gender conformity pressure impacts female adolescents' behavior only from a particular threshold, which is higher than the level of gender conformity pressure observed among the female adolescents in our study. However, because previous studies found that pressure is negatively related to male and female students' wellbeing and psychosocial adjustment (Egan and Perry 2001; Yunger et al. 2004), it is important to keep in mind that a low level of gender conformity pressure seems desirable for both male and female adolescents.

Our finding that gender conformity pressure did not predict school misconduct in female adolescents is interesting not only from a theoretical perspective but also as an empirical result in itself because few studies have analyzed whether variables predict school misconduct differently for males and females (Bertrand and Pan 2013; Demanet et al. 2013). Moreover, it raises the question of what else might cause school misconduct in female adolescents. In a U.S. sample of more than 3800 female adolescents, low school bonding and a low self-perceived reputation predicted higher levels of school misconduct (Lee and Smith-Adcock 2005). This result is in line with research based on samples including female adolescents and male adolescents on the role of related constructs of study involvement (Demanet et al. 2013) and selfesteem (Zimmermann et al. 2013; for summaries of research on predictors of school misconduct in general, see Demanet 2013; Smith-Adcock et al. 2013).

Low socioeconomic status, low parental involvement in a child's schooling, and a low commitment to non-sport activities have been found to predict school misconduct to a similar extent in male and female adolescents (Hart and Mueller 2013). Hart and Mueller (2013) furthermore identified school bonding as a stronger negative predictor in male than in female adolescents. Additionally, they identified commitment to sports activities as a positive predictor of school misconduct only in male and not in female adolescents, as well as students' beliefs about what counts in life as a negative predictor only in male and not in female adolescents. None of the variables studied by Hart and Mueller (2013) was better suited for predicting female adolescents' than male adolescents' school misconduct. Although female adolescents' problem behavior out of school has recently gained some attention (Kerr et al. 2011), why female adolescents misbehave in school remains an open question. Our findings suggest that it would be fruitful for future researchers to look at factors other than students' felt pressure to conform to gender stereotypes.

\section{Limitations}

One limitation of our study is that academic achievement was measured only in the first wave. Thus, we could not study how the gender-specific effects of gender conformity pressure on school misconduct transform into gender differences in academic achievement at the expense of male adolescents (see DiPrete and Jennings 2012; Owens 2016). Moreover, due to the fact that there were only three waves, we could predict growth rates, but could not draw conclusions on predictors of growth acceleration in school misconduct of male and female adolescents with different levels of pressure for gender conformity. Thus, longitudinal data including more than three time points is needed.

Furthermore, in future studies, it seems promising to complement students' felt pressure for gender conformity with measures of the pressure actually exerted by students on their peers to behave in a stereotype-conforming way (i.e., their sanctioning of counter-stereotypical behavior). Unfortunately, no such measure was included in our dataset. Moreover, our study was based in Flanders, Belgium. Because gender stereotypes and school norms can vary between countries and cultures and over time (Nosek et al. 2009; Wilde and Diekman 2005), our findings cannot be easily generalized. Finally, we focused on students aged 12 to 14 years-old. In future research, it would be interesting to study a longer period of time in order to determine how the prevalence of school misconduct in male and female adolescents develops as students move through puberty.

\section{Future Research Directions}

Above and beyond the impulses for future research that directly follow this study's limitations, the following directions seem fruitful for future research. In sum, our study found that male adolescents especially were vulnerable to pressure for gender conformity. Their misconduct and its increase were related to this pressure, whereas female adolescents' misconduct was not. A next step for future research would be to examine whether the relationships established in our study hold for all male adolescents or whether interactions with, for instance, socioeconomic status or ethnicity need to be accounted for. Employing data from France, Hoffman et al. (2019) found that the development of gender conformity pressure in adolescence was dependent on students' gender and ethnicity. Pressure for gender conformity remained stable for French male adolescents of European descent, whereas pressure increased for French male adolescents of North African descent. For female adolescents, no ethnicity-specific differences were found. This pattern raises the possibility that the 
formation of male adolescents' gender identity might depend more strongly on their ethnic or cultural background than female adolescents'. There may be gender- and ethnicityspecific relations between gender conformity pressure and school misconduct. Moreover, gender conformity pressure and ethnicity conformity pressure might interact (Aoyagi et al. 2018). It seems fruitful for future research to study their intersecting contribution in predicting school-related variables because this focus was beyond the current study scope.

Regarding socioeconomic status, it has been argued that particularly in low socioeconomic status contexts, male adolescents construct masculinity in a way that clashes with school norms (Legewie and DiPrete 2012; Van Hek et al. 2018). This relates to the concept of "laddishness," which was first identified as a manner of enacting masculinity among working-class male adolescents (Willis 1977) and later extended to middle-class male adolescents (Francis 1999). Against this background, a promising avenue for future research would be to test whether larger negative effects of gender conformity pressure on precursors of academic achievement exist for male adolescents from or in low versus high socioeconomic status contexts. Because the present data covered the first 2 years of secondary school in Flanders, only negligible school effects were to be expected. Indeed, less than $5 \%$ variation in school misconduct between schools was found, indicating the need for more extensive data to address the question of school effects.

Related to this point, another possible direction for future research would be to assess the influence of peer networks on students' felt pressure to adhere to gender norms and gender differences in outcomes such as school misconduct. Existing literature that proposes a link between the school context and the gender gap in academic achievement mostly theorizes on differences in gender norms between peer groups in school (Legewie and DiPrete 2012). Future research could assess whether gender stereotypes in school or in smaller peer groups matter most for the extent of gender conformity pressure students feel. Unfortunately, our data did not include information on students' peer network.

\section{Practice Implications}

Our study is important not only for the scientific community but also for teachers and counselors because our results focus attention on the pivotal role of gender conformity pressure in male students' development of school misconduct during adolescence. First, awareness of this effect will help teachers understand such behavior as an unfavorable consequence of male identity formation and enactment of masculinity in adolescence - and not merely as a rejection of school or questioning of teachers' authority and values. Such an understanding might help teachers cope with students' misbehavior, which is important because prior research identifies student misbehavior as a major stressor among teachers (Aloe et al. 2014). Second, our findings point to the importance of developing strategies to tackle pressure on male adolescents to conform to traditional stereotypes in order to reduce the negative effects of these stereotypes on male adolescents' school conduct. This can have long-term benefits for male adolescents' educational careers. For instance, (gender) diversity programs could foster school communities that value diversity in how gender is constructed and in which everybody is an accepted member irrespective of how she or he fits in with current gender-stereotyped expectations.

\section{Conclusion}

Student misconduct is part of the daily routine in most schools, although it has detrimental effects on learning (Zimmermann et al. 2013) and on teachers' occupational well-being (Aloe et al. 2014; Evers et al. 2004). It is important to better understand the origins of school misconduct in order to find ways to prevent it. Based on three-wave panel data from Flemish adolescents, we found a steeper increase in school misconduct in male than in female early adolescents. This pattern was partly explained by the pressure male adolescents felt to conform to gender stereotypes. For female adolescents, no relation between gender conformity pressure and school misconduct was found. Our findings advance knowledge on the potential conflict between the male gender role and the student role (Mickelson 1989; Morris 2012), illustrating once more the detrimental effects of gender stereotypes on male adolescents' educational trajectories. Our findings also underline the need to develop and study strategies to build school communities in which diverse constructions of gender are present and valued.

Acknowledgements We would like to acknowledge the project "Teaching in the bed of Procrustes," financed by the Agency for Innovation by Science and Technology (Project Number: SBO 110020), which made the present research possible. Furthermore, this publication was sponsored by the College for Interdisciplinary Educational Research, a joint initiative of the BMBF, the Jacobs Foundation, and the Leibniz Association.

Funding Information Open Access funding provided by Projekt DEAL.

\section{Compliance with Ethical Standards}

In this study, survey data on adolescents (7th graders) is used. The use of child assent was approved by the schools and the Belgian Commission for the Protection of Privacy, based on the minimal risk of the study. Anonymity was guaranteed. 
Open Access This article is licensed under a Creative Commons Attribution 4.0 International License, which permits use, sharing, adaptation, distribution and reproduction in any medium or format, as long as you give appropriate credit to the original author(s) and the source, provide a link to the Creative Commons licence, and indicate if changes were made. The images or other third party material in this article are included in the article's Creative Commons licence, unless indicated otherwise in a credit line to the material. If material is not included in the article's Creative Commons licence and your intended use is not permitted by statutory regulation or exceeds the permitted use, you will need to obtain permission directly from the copyright holder. To view a copy of this licence, visit http://creativecommons.org/licenses/by/4.0/.

\section{References}

Aloe, A. M., Shisler, S. M., Norris, B. D., Nickerson, A. B., \& Rinker, T. W. (2014). A multivariate meta-analysis of student misbehavior and teacher burnout. Educational Research Review, 12, 30-44. https:// doi.org/10.1016/j.edurev.2014.05.003.

Aoyagi, K., Santos, C. E., \& Updegraff, K. A. (2018). Longitudinal associations between gender and ethnic-racial identity felt pressure from family and peers and self-esteem among African American and Latino/a youth. Journal of Youth and Adolescence, 47, 207-221. https://doi.org/10.1007/s10964-017-0750-0.

Bandura, A. (1997). Self-efficacy: The exercise of control. New York: Freeman.

Beaman, R., Wheldall, K., \& Kemp, C. (2006). Differential teacher attention to boys and girls in the classroom. Educational Review, 58, 339-366. https://doi.org/10.1080/00131910600748406.

Bem, S. L. (1981). Gender schema theory: A cognitive account of sex typing. Psychological Review, 88, 354-364. https://doi.org/10.1037/ 0033-295X.88.4.354

Bertrand, M., \& Pan, J. (2013). The trouble with boys: Social influences and the gender gap in disruptive behavior. American Economic Journal: Applied Economics, 5, 32-64. https://doi.org/10.1257/ app.5.1.32.

Blakemore, J. E. O. (2003). Children's beliefs about violating gender norms: Boys shouldn't look like girls, and girls shouldn't act like boys. Sex Roles, 48, 411-419. https://doi.org/10.1023/A: 1023574427720.

Breslau, N., Breslau, J., Miller, E., \& Raykov, T. (2011). Behavior problems at ages 6 and 11 and high school academic achievement: Longitudinal latent variable modeling. Psychiatry Research, 185, 433-437. https://doi.org/10.1016/j.psychres.2010.07.027.

Bussey, K., \& Bandura, A. (1999). Social cognitive theory of gender development and differentiation. Psychological Review, 106, 676713. https://doi.org/10.1037/0033-295X.106.4.676.

Crosnoe, R. (2002). High school curriculum track and adolescent association with delinquent friends. Journal of Adolescent Research, 17, 143-167. https://doi.org/10.1177/0743558402172003.

Demanet, J. (2013). We don't need no education! A multilevel inquiry into the compositional and cultural school determinants of school misconduct. Ghent University, Department of Sociology, Ghent.

Demanet, J., \& Van Houtte, M. (2011). Social-ethnic school composition and school misconduct: Does sense of futility clarify the picture? Sociological Spectrum, 31, 224-256. https://doi.org/10.1080/ 02732173.2011.541343.

Demanet, J., \& Van Houtte, M. (2012a). School belonging and school misconduct: The differing role of teacher and peer attachment. Journal of Youth and Adolescence, 41, 499-514. https://doi.org/10. 1007/s10964-011-9674-2.
Demanet, J., \& Van Houtte, M. (2012b). Teachers' attitudes and students' opposition. School misconduct as a reaction to teachers' diminished effort and affect. Teaching and Teacher Education, 28, 860-869. https://doi.org/10.1016/j.tate.2012.03.008.

Demanet, J., \& Van Houtte, M. (2019). Socioeconomic status, economic deprivation, and school misconduct: An inquiry into the role of academic self-efficacy in four European cities. Social Psychology of Education, 22, 1-22. https://doi.org/10.1007/s11218-018-9470-x.

Demanet, J., Vanderwegen, P., Vermeersch, H., \& Van Houtte, M. (2013). Unravelling gender composition effects on rule-breaking at school: A focus on study attitudes. Gender and Education, 25, 466-485. https://doi.org/10.1080/09540253.2013.772567.

Derks, A., \& Vermeersch, H. (2001). Gender en schools presteren: Een multilevel-analyse naar de oorzaken van de grotere schoolachterstand van jongens in het Vlaams secundair onderwijs [gender and scholastic achievement: A multi-level analysis into the causes of boys' higher school delay in Flemish secondary education]. Brussels: Ministry of the Flemish Community, Education Department (Vol. 26): TOR.

DiPrete, T. A., \& Jennings, J. L. (2012). Social and behavioral skills and the gender gap in early educational achievement. Social Science Research, 41, 1-15. https://doi.org/10.1016/j.ssresearch.2011.09. 001.

Donnellan, M. B., Trzesniewski, K. H., Robins, R. W., Moffitt, T. E., \& Caspi, A. (2005). Low self-esteem is related to aggression, antisocial behavior, and delinquency. Psychological Science, 16, 328-335. https://doi.org/10.1111/j.0956-7976.2005.01535.x.

Downey, D. B., \& Vogt Yuan, A. S. (2005). Sex differences in school performance during high school: Puzzling patterns and possible explanations. The Sociological Quarterly, 46, 299-321. https://doi. org/10.1111/j.1533-8525.2005.00014.x.

Dudal, P. (2003). Oriënteringstest wiskunde 6 [orientation test in mathematics for 6th grade]. Brussel: VCLB Service.

Duke, D. L. (1978). Why don't girls misbehave more than boys in school? Journal of Youth and Adolescence, 7, 141-157. https://doi.org/10. 1007/BF01537522.

Duncan, S. C., Duncan, T. E., \& Strycker, L. A. (2001). Qualitative and quantitative shifts in adolescent problem behavior development: A cohort-sequential multivariate latent growth modeling approach. Journal of Psychopathology and Behavioral Assessment, 23, 4350. https://doi.org/10.1023/A:1011091523808.

Egan, S. K., \& Perry, D. G. (2001). Gender identity: A multidimensional analysis with implications for psychosocial adjustment. Developmental Psychology, 37, 451-463. https://doi.org/10.1037/ 0012-1649.37.4.451.

Else-Quest, N. M., Hyde, J. S., \& Linn, M. C. (2010). Cross-national patterns of gender differences in mathematics: A meta-analysis. Psychological Bulletin, 136, 103-127. https://doi.org/10.1037/ a0018053.

Erikson, E. H. (1968). Identity: Youth and crisis. New York: Norton.

Erikson, R., \& Goldthorpe, J. H. (1992). The constant flux: A study of class mobility in industrial countries. New York: Oxford University Press.

Erikson, R., \& Goldthorpe, J. H. (2002). Intergenerational inequality: A sociological perspective. Journal of Economic Perspectives, 16, 3144. https://doi.org/10.1257/089533002760278695.

Evers, W. J. G., Tomic, W., \& Brouwers, A. (2004). Burnout among teachers. School Psychology International, 25, 131-148. https:// doi.org/10.1177/0143034304043670.

Forehand, R., Middletin, K., \& Long, N. (1987). Adolescent functioning as a consequence of recent parental divorce and the parentaladolescent relationship. Journal of Applied Developmental Psychology, 8, 305-315. https://doi.org/10.1016/0193-3973(87) 90006-2.

Francis, B. (1999). Lads, lasses and (new) labour: 14-16-year-old students' responses to the 'laddish behaviour and boys' 
underachievement' debate. British Journal of Sociology of Education, 20, 355-371. https://doi.org/10.1080/01425699995317.

Geven, S., Jonsson, J. O., \& van Tubergen, F. (2017). Gender differences in resistance to schooling: The role of dynamic peer-influence and selection processes. Journal of Youth and Adolescence, 46, 24212445. https://doi.org/10.1007/s10964-017-0696-2.

Glock, S., \& Kleen, H. (2017). Gender and student misbehavior: Evidence from implicit and explicit measures. Teaching and Teacher Education, 67, 93-103. https://doi.org/10.1016/j.tate. 2017.05.015.

Hart, C. O., \& Mueller, C. E. (2013). School delinquency and social bond factors: Exploring gendered differences among a national sample of 10th graders. Psychology in the Schools, 50, 116-133. https://doi. org/10.1002/pits.21662.

Heckman, J. J., \& Lafontaine, P. A. (2010). The American high school graduation rate: Trends and levels. The Review of Economics and Statistics, 92, 244-262. https://doi.org/10.1162/rest.2010.12366.

Heyder, A., \& Kessels, U. (2015). Do teachers equate male and masculine with lower academic engagement? How student's gender enactment triggers gender stereotypes at school. Social Psychology of Education, 18, 467-485. https://doi.org/10.1007/s11218-0159303-0.

Heyder, A., \& Kessels, U. (2017). Boys don't work? On the psychological benefits of showing low effort in high school. Sex Roles, 77, 72 85. https://doi.org/10.1007/s11199-016-0683-1.

Heyder, A., Kessels, U., \& Steinmayr, R. (2017). Explaining academictrack boys' underachievement in language grades: Not a lack of aptitude but students' motivational beliefs and parents' perceptions? British Journal of Educational Psychology, 87, 205-223. https://doi. org/10.1111/bjep.12145.

Hill, J., \& Lynch, M. (1983). The intensification of gender-related role expectations during early adolescence. In J. Brooks-Gunn \& A. C. Petersen (Eds.), Girls at puberty. Biological and psychosocial perspectives (pp. 201-228). New York: Plenum.

Hinshaw, S. P. (1992). Externalizing behavior problems and academic underachievement in childhood and adolescence: Causal relationships and underlying mechanisms. Psychological Bulletin, 111, 127-155. https://doi.org/10.1037/0033-2909.111.1.127.

Hoffman, A. J., Dumas, F., Loose, F., Smeding, A., Kurtz-Costes, B., \& Régner, I. (2019). Development of gender typicality and felt pressure in European French and north African French adolescents. Child Development, 90, e306-e321. https://doi.org/10.1111/cdev. 12959.

Huyge, E., van Maele, D., \& Van Houtte, M. (2014). Does students' machismo fit in school? Clarifying the implications of traditional gender role ideology for school belonging. Gender and Education, 1-18. https://doi.org/10.1080/09540253.2014.972921

Jackson, C. (2002). 'Laddishness' as a self-worth protection strategy. Gender and Education, 14, 37-50. https://doi.org/10.1080/ 09540250120098870.

Jackson, C. (2003). Motives for 'laddishness' at school: Fear of failure and fear of the 'feminine'. British Educational Research Journal, 29, 583-598. https://doi.org/10.1080/01411920301847.

Jenkins, P. H. (1995). School delinquency and school commitment. Sociology of Education, 68, 221-239. https://doi.org/10.2307/ 2112686.

Jones, S., \& Myhill, D. (2004). 'Troublesome boys' and 'compliant girls': Gender identity and perceptions of achievement and underachievement. British Journal of Sociology of Education, 25, 547-561. https://doi.org/10.1080/0142569042000252044.

Kerr, M., Stattin, H., Engels, R. C. M. E., Overbeek, G., \& Andershed, A.-K. (2011). Understanding girls' problem behavior: How girls' delinquency develops in the context of maturity and health, cooccurring problems, and relationships. Chichester: WileyBlackwell.
Kessels, U., \& Heyder, A. (2017). Die Wertschätzung schulischer Anstrengung als mediator von Geschlechtsunterschieden in Noten [personal value placed on academic effort as a mediator of gender differences in grades: A domain-specific analysis]. Zeitschrift für Entwicklungspsychologie und Pädagogische Psychologie, 49, 8697. https://doi.org/10.1026/0049-8637/a000171

Kessels, U., Heyder, A., Latsch, M., \& Hannover, B. (2014). How gender differences in academic engagement relate to students' gender identity. Educational Research, 56, 219-228. https://doi.org/10.1080/ 00131881.2014 .898916

Keyes, C. L. M., Shmotkin, D., \& Ryff, C. D. (2002). Optimizing wellbeing: The empirical encounter of two traditions. Journal of Personality and Social Psychology, 82, 1007-1022. https://doi.org/ 10.1037/0022-3514.82.6.1007.

Lagaert, S., Van Houtte, M., \& Roose, H. (2017). Engendering culture: The relationship of gender identity and pressure for gender conformity with adolescents' interests in the arts and literature. Sex Roles, 77, 482-495. https://doi.org/10.1007/s11199-017-0738-y.

Lam, S.-F., Jimerson, S., Kikas, E., Cefai, C., Veiga, F. H., Nelson, B., ... Zollneritsch, J. (2012). Do girls and boys perceive themselves as equally engaged in school? The results of an international study from 12 countries. Journal of School Psychology, 50, 77-94. https://doi.org/10.1016/j.jsp.2011.07.004

Lee, S. M., \& Smith-Adcock, S. (2005). A model of girls' school delinquency: School bonding and reputation. Professional School Counseling, 9, 78-87. https://doi.org/10.1177/ 2156759X0500900110.

Legewie, J., \& DiPrete, T. A. (2012). School context and the gender gap in educational achievement. American Sociological Review, 77, 463-485. https://doi.org/10.1177/0003122412440802.

Lynch, R. J., Kistner, J. A., \& Allan, N. P. (2014). Distinguishing among disruptive behaviors to help predict high school graduation: Does gender matter? Journal of School Psychology, 52, 407-418. https:// doi.org/10.1016/j.jsp.2014.05.001.

Lyng, S. T. (2009). Is there more to "antischoolishness" than masculinity?: On multiple student styles, gender, and educational selfexclusion in secondary school. Men and Masculinities, 11, 462487. https://doi.org/10.1177/1097184X06298780.

Marks, G. N. (2008). Accounting for the gender gaps in student performance in reading and mathematics: Evidence from 31 countries. Oxford Review of Education, 34, 89-109. https://doi.org/10.1080/ 03054980701565279 .

McKenney, S. J., \& Bigler, R. S. (2016). High heels, low grades: Internalized sexualization and academic orientation among adolescent girls. Journal of Research on Adolescence, 26, 30-36. https:// doi.org/10.1111/jora.12179.

Mickelson, R. A. (1989). Why does Jane read and write so well? The anomaly of women's achievement. Sociology of Education, 62, 4763. https://doi.org/10.2307/2112823.

Morris, E. W. (2012). Learning the hard way: Masculinity, place, and the gender gap in education. The Rutgers series in childhood studies. New Brunswick: Rutgers University Press.

Negriff, S., \& Susman, E. J. (2011). Pubertal timing, depression, and externalizing problems: A framework, review, and examination of gender differences. Journal of Research on Adolescence, 21, 717746. https://doi.org/10.1111/j.1532-7795.2010.00708.x.

Nosek, B. A., \& Smyth, F. L. (2011). Implicit social cognitions predict sex differences in math engagement and achievement. American Educational Research Journal, 48, 1125-1156. https://doi.org/10. 3102/0002831211410683.

Nosek, B. A., Smyth, F. L., Sriram, N., Lindner, N. M., Devos, T., Ayala, A., ... Greenwald, A. G. (2009). National differences in genderscience stereotypes predict national sex differences in science and math achievement. Proceedings of the National Academy of Sciences of the United States of America, 106, 10593-10597. https://doi.org/10.1073/pnas.0809921106. 
Owens, J. (2016). Early childhood behavior problems and the gender gap in educational attainment in the United States. Sociology of Education, 89, 236-258. https://doi.org/10.1177/ 0038040716650926.

Singer, J., \& Willett, J. B. (2003). Applied longitudinal data analysis: Modeling change and event occurrence. Oxford: Oxford University Press.

Sirsch, U. (2003). The impending transition from primary to secondary school: Challenge or threat? International Journal of Behavioral Development, 27, 385-395. https://doi.org/10.1080/ 01650250344000082 .

Skinner, O. D., Kurtz-Costes, B., Wood, D., \& Rowley, S. J. (2018). Gender typicality, felt pressure for gender conformity, racial centrality, and self-esteem in African American adolescents. Journal of Black Psychology, 44, 195-218. https://doi.org/10.1177/ 0095798418764244.

Skočajić, M. M., Radosavljević, J. G., Okičić, M. G., Janković, I. O., \& Žeželj, I. L. (2019). Boys just don't! Gender stereotyping and sanctioning of counter-stereotypical behavior in preschoolers. Sex Roles, 67, 65-172. https://doi.org/10.1007/s11199-019-01051-x.

Smith-Adcock, S., Lee, S. M., Kerpelman, J., Majuta, A., \& Young, C. B. (2013). Reputation enhancement and school delinquency. Youth \& Society, 45, 201-220. https://doi.org/10.1177/0044118X11410895.

Snijders, T. A. B., \& Bosker, R. J. (2012). Multilevel analysis: An introduction to basic and advanced multilevel modeling (2nd ed.). Los Angeles: Sage.

Starr, C. R., \& Zurbriggen, E. L. (2017). Sandra Bem's gender schema theory after 34 years: A review of its reach and impact. Sex Roles, 76, 566-578. https://doi.org/10.1007/s11199-016-0591-4.

Steinberg, L., \& Monahan, K. C. (2007). Age differences in resistance to peer influence. Developmental Psychology, 43, 1531-1543. https:// doi.org/10.1037/0012-1649.43.6.1531.

Stewart, E. A. (2003). School social bonds, school climate, and school misbehavior: A multilevel analysis. Justice Quarterly, 20, 575-604. https://doi.org/10.1080/07418820300095621.

Stoet, G., \& Geary, D. C. (2013). Sex differences in mathematics and reading achievement are inversely related: Within- and acrossnation assessment of 10 years of PISA data. PLoS One, 8, e57988. https://doi.org/10.1371/journal.pone.0057988.

Stoet, G., \& Geary, D. C. (2015). Sex differences in academic achievement are not related to political, economic, or social equality. Intelligence, 48, 137-151. https://doi.org/10.1016/j.intell.2014.11. 006.

Sullivan, A. M., Johnson, B., Owens, L., \& Conway, R. (2014). Punish them or engage them?: Teachers' views of unproductive student behaviours in the classroom. Australian Journal of Teacher Education, 39, 43-56. https://doi.org/10.14221/ajte.2014v39n6.6.

Usher, E. L., Li, C. R., Butz, A. R., \& Rojas, J. P. (2019). Perseverant grit and self-efficacy: Are both essential for children's academic success? Journal of Educational Psychology, 111, 877-902. https:// doi.org/10.1037/edu0000324.

Van Hek, M., Kraaykamp, G., \& Wolbers, M. H. J. (2016). Comparing the gender gap in educational attainment: The impact of emancipatory contexts in 33 cohorts across 33 countries. Educational Research and Evaluation, 22, 260-282. https://doi.org/10.1080/ 13803611.2016.1256222.

Van Hek, M., Kraaykamp, G., \& Pelzer, B. (2018). Do schools affect girls' and boys' reading performance differently? A multilevel study on the gendered effects of school resources and school practices. School Effectiveness and School Improvement, 29, 1-21. https:// doi.org/10.1080/09243453.2017.1382540.

Van Houtte, M. (2004). Gender context of the school and study culture, or how the presence of girls affects the achievement of boys. Educational Studies, 30, 409-423. https://doi.org/10.1080/ 0305569042000310336 .
Van Houtte, M., \& Stevens, P. A. (2008). Sense of futility: The missing link between track position and self-reported school misconduct. Youth \& Society, 20, 245-264. https://doi.org/10.1177/ 0044118 X08316251.

Vantieghem, W. (2016). Gender goes to school: The influence of gender norms on early adolescents' school functioning (unpublished doctoral dissertation). Ghent: Ghent University. Retrieved from https:// biblio.ugent.be/record/7023823

Vantieghem, W., \& Van Houtte, M. (2015). Are girls more resilient to gender-conformity pressure? The association between genderconformity pressure and academic self-efficacy. Sex Roles, 73, 115. https://doi.org/10.1007/s11199-015-0509-6.

Vantieghem, W., Vermeersch, H., \& Van Houtte, M. (2014). Why "gender" disappeared from the gender gap: (re-)introducing gender identity theory to educational gender gap research. Social Psychology of Education, 17, 357-381. https://doi.org/10.1007/ s11218-014-9248-8.

Veenstra, R., Dijkstra, J. K., Steglich, C., \& Van Zalk, M. H. W. (2013). Network-behavior dynamics. Journal of Research on Adolescence, 23, 399-412. https://doi.org/10.1111/jora.12070.

Vermeersch, H., T'Sjoen, G., Kaufman, J. M., Vincke, J., \& Van Houtte, M. (2010). Gender ideology, same-sex peer group affiliation and the relationship between testosterone and dominance in adolescent boys and girls. Journal of Biosocial Science, 42, 463-475. https://doi.org/ 10.1017/S0021932010000106.

Véronneau, M.-H., \& Dishion, T. J. (2010). Predicting change in early adolescent problem behavior in the middle school years: A mesosystemic perspective on parenting and peer experiences. Journal of Abnormal Child Psychology, 38, 1125-1137. https:// doi.org/10.1007/s10802-010-9431-0.

Voyer, D., \& Voyer, S. D. (2014). Gender differences in scholastic achievement: A meta-analysis. Psychological Bulletin, 140, 1174 1204. https://doi.org/10.1037/a0036620.

Wang, M.-T., Willett, J. B., \& Eccles, J. S. (2011). The assessment of school engagement: Examining dimensionality and measurement invariance by gender and race/ethnicity. Journal of School Psychology, 49, 465-480. https://doi.org/10.1016/j.jsp.2011.04.001.

Wang, M.-T., Eccles, J. S., \& Kenny, S. (2013). Not lack of ability but more choice: Individual and gender differences in choice of careers in science, technology, engineering, and mathematics. Psychological Science, 24, 770-775. https://doi.org/10.1177/ 0956797612458937.

Wilbourn, M. P., \& Kee, D. W. (2010). Henry the nurse is a doctor too: Implicitly examining children's gender stereotypes for male and female occupational roles. Sex Roles, 62, 670-683. https://doi.org/ 10.1007/s11199-010-9773-7.

Wilde, A., \& Diekman, A. B. (2005). Cross-cultural similarities and differences in dynamic stereotypes: A comparison between Germany and the United States. Psychology of Women Quarterly, 29, 188196. https://doi.org/10.1111/j.1471-6402.2005.00181.x.

Willis, P. E. (1977). Learning to labour: How working class kids get working class jobs. New York: Columbia University Press.

Yunger, J. L., Carver, P. R., \& Perry, D. G. (2004). Does gender identity influence children's psychological well-being? Developmental Psychology, 40, 572-582. https://doi.org/10.1037/0012-1649.40.4. 572.

Zimmermann, F., Schütte, K., Taskinen, P., \& Köller, O. (2013). Reciprocal effects between adolescent externalizing problems and measures of achievement. Journal of Educational Psychology, 105, 747-761. https://doi.org/10.1037/a0032793.

Publisher's Note Springer Nature remains neutral with regard to jurisdictional claims in published maps and institutional affiliations. 